\title{
THE EFFECTS OF SOCIAL MEDIA ON YOUTH'S INTERPERSONAL COMMUNICATION IN UAE
}

\author{
Viola Gjylbegaj $^{1 *}$, Osama Jararaa ${ }^{2}$ \\ ${ }^{1}$ Assist. Prof. Dr. Viola Gjylbegaj, Abu Dhabi University, United Arab Emirates, \\ viola.gjylbegaj@adu.ac.ae \\ ${ }^{2}$ Adjuct. Prof. Osama Jararaa, Abu Dhabi University, United Arab Emirates, \\ o.jararaa-adjunct@adu.ac.ae \\ ${ }^{*}$ Corresponding author
}

\begin{abstract}
Social media is an important tool that allows people to communicate with others. There are many advantages of using the social media, but one of the most serious challenges that the youth is facing, is that, it is affecting their interpersonal communication. For example, they use social media to share their feelings instead of face to face communication. The objective of the research is to identity the degree of how social media affects the youth's interpersonal communication in UAE. Also, we will explore the factors that lead the youth to express, share their feelings and problems in the virtual world. Moreover, we will investigate the consequences of the virtual world on the youth's interpersonal communication. Finally, we will list the possible solutions. Survey will be conducted as a methodology and it will be distributed to the youth population living in UAE. The social media affects the interpersonal communication negatively more than positively and it will be explained clearly in the paper.
\end{abstract}

Keywords: Interpersonal communication, Social Media, UAE.

\section{INTRODUCTION}

Today, 80 to $90 \%$ of humans conduct their daily life activities and learn about the world through interpersonal communication, or "IPC". Interpersonal communication is the practice of exchanging information between two or more people in a face to face communication setting. Moreover, it depends on the quality of the communication itself. Interpersonal communication is a very important part of humans' lives and allows them to conduct both physical and mental movements; however, the majority of the world's population has been shifting their communication roles from interpersonal communication (face to face communication) to an electronic communication, which is through the access of the Social Media. (DeVito, 2008). Social Media, the most welcoming electronic communication platform, brings the enormous globe into a small village. It narrows the route of human communication across the vast globe. Seemingly, it comprises these noteworthy interactive communication tools such as Wikipedia, Facebook, Instagram, Twitter, Skype, etc. (Andreas M. Kaplan, Michael Haenlein, 2010). Social media could be defined as an electronic communication tool where 
the users share their info, ideas, personal messages and videos with the public. (Ghaffar, 2012). Without the existence of Social Media, there is no way to globalization and contacts establishment. All the global activities are operated through the power of Social Media technologies. (Valley, 2015). Our segment for this research is the youth generation aged from 15 up to 25 living in UAE. And the reason for choosing this particular segment is because UAE is rated as the country with the highest time spent on social media sites, among all the countries in the Middle East. A large number of social media users are the youth aged from 15 -29. (Kemp, 2014). The purpose of conducting this research is to discover: To what extent the social media destruct the youth's interpersonal communication in UAE. It is a very important research to understand the reasons behind the problem.

\section{LITERATURE REVIEW}

Interpersonal communication is one of the major elements that keeps us alive because it is impossible for the human beings to live alone. The interpersonal communication theory is being described as the 'System perspective' which takes an "Interactional view of relationship maintenance by focusing on repeated and interdependent dealings", by Dainton (Dainton, 2004). We start practicing the interpersonal communication skills even before we are born by responding to the movements and sounds. Once we become aware of someone, we contact them and we continue to build contacts till the end of our lives.

Indeed, there are several factors that induce the youth to access Social Media for initiating interpersonal communication. They believe that it is the only channel from where they can learn about a person's true personality and about their background lives. Firstly, it assists the youth to get responses much quicker than the direct communication. Secondly, whenever there is an interaction between two people in a direct meeting, it has been discovered that they often feel uncomfortable to disclose their personal opinion about different issues due to avoiding any physical harm from those with whom they are interacting. In fact, whenever there is a discussion between person to person regarding serious issues, they are more likely to overreact and punish them if one does not agree with the others' personal judgments towards the issues. This particular practice is quite evident among the youth community because they do not have much patience to digest different views. They prefer that everyone's opinion could match with what the majority expects. It is because they lack proper knowledge on certain fields; as a result, they shape their opinion and discuss what they believe it is right instead of going through a deep research on a particular issue. For example, Facebook and Twitter are some of the sites where young adults are inclined to share their personal issues with those who are not really their friends, in the Middle East. Thirdly, what motivates them to browse Social Media sites blindly for an interpersonal communication is that they believe strangers or their virtual friends are open minded and they can understand the problems they face more than their families. As a result, they get immediate solutions of whatever concerns they have in their lives from their contacts, because they do not make enough judgments. They fear that if they discuss personal matter with their friends face to face, then they might get assaulted. It has been reported that a large number of young adults are physically wounded in friends gathering whenever there is a disagreement on serious issues. This is why the youth prefer to make any discussion regarding personal matter through social media in order to avoid any physical injury and negative impression from others. (Staff, 2013).

Nowadays, social media plays an effective role in altering the communication pattern among people. It affects the young adults who are mainly using the social media both in positive and negative ways. Social media comprises of these noteworthy interactive communication tools such as Facebook, Instagram, Twitter, Google +, Skype, Yahoo, and Linkedln which are the most desirable sites where the young adults spend most of their leisure time during the day. The statistics show that $56 \%$ of the young adults rely on collecting all types of information from Facebook. (Maeve Duggan, Nicole B. Ellison, Cliffe Lampe, Amanda Lenhart \& Mary Madden, 2015). Middle East is ranked as the third highest for visiting social media sites through mobile by the youth. (Andreas M. Kaplan, Michael Haenlein, 2010). Social media has several advantages that benefit the youth's interpersonal skills. Firstly, it assists them to expand their network with more people from different parts of the world. For example, they can meet virtually groups of people that share the same interests and meet their expectations about certain issues. Therefore, they build contact with them and share their point of view. (Jain, 2010). Secondly, social media improves their interpersonal communication skills to great extent by knowing the power of the social media and its significant role in their lives. Because young adults should not use the social media only as a tool of entertainment but they should also use it for communication. Moreover, we live in an environment where we have to face people from different cultural background, so youth should have enough knowledge on using the proper language during online conversations. The social media give them the opportunity to enhance their language skills and this would result in a good communication setting. Finally, without the existence of Social Media, there is no way to globalization and contacts establishment. All the global activities are operated through the power of Social Media technologies. (Valley, 2015). 
However, social media as a communication tool could also affect their social and interpersonal skills in a destructive way. Since Social Media opens the way to receiving feedbacks from the respondents, this is the moment when the online users are active in instant communication with others. Through spending time on Social Media Sites, a big percentage of the online users share their personal opinions and feelings toward disputable issues. This kind of practice is quite evident among the youth population because they are the only ones more engrossed in commenting and sharing their point of view to others more than the old aged population. For example, social media distracts the majority of the youth and make them feel they are independent from their families and that they can trust those group of contacts who are actually strangers or distant friends. Every hour, the young adults are tightly engaged in scanning their smartphones and log into the social media sites and share their profiles and personal status with those who are not trustworthy rather than having face to face communication with their loved ones. (Al-Sayegh, 2013). In brief, this is a crucial concern among the Mass Media Researchers today, but not much research is done on how social media affects the youths' interpersonal communication in UAE and what can be done to minimize the effects of social media among the youth community.

Social Media has changed the practices of the youth daily activities for example during the special occasions such as on EID, Ramadan, New Year, Christmas and on some other religious occasions. The young adults send their wishes to their friends and families through Social Media. It is because they are not always able to meet all their friends and relatives face to face across UAE and the world. As there is a sharp demand on utilizing the new media technologies specially the smartphones, laptops, notebooks and so on, the greater number of the youth in UAE has changed their communication pattern concept between their families, old and new friends and their loved ones, than about 10 years ago. Every time, whenever there is the opportunity to interact with the families face to face, young adults are engaged into mobile phones. While they focus on using mobile phones, they log in to the Social Media sites for chatting unnecessarily with their friends and with those who they don't really know. To conclude, it is found that the reason why the youth in UAE do not maintain close ties with their families and loved ones, is because of the degree of the behavioral acceptance. The families would not accept their youth to adopt wrong behavioral practices, but the friends or those that they don't really know, will always motivate them to adopt the wrong behavioral practices.

(AI-Sayegh, The Impact of Social Media on UAE Society, 2013)

\section{METHODOLOGY AND RESULTS}

\subsection{Quantitative Method: Survey Significance}

An online survey (Survey Planet) was conducted in order to reach a large number of the youth population across UAE. It was distributed to 201 young adults in UAE. The total number of male respondents is 91 , and the total number of female respondents is 109 .

The below table shows the results of the survey.

Table 1: Results of the survey questions

\begin{tabular}{|c|c|c|c|c|c|c|c|}
\hline Question & \multicolumn{7}{|c|}{ Answer } \\
\hline \multirow[t]{2}{*}{ 1.The age range } & \multicolumn{4}{|c|}{$15-20$} & \multicolumn{3}{|c|}{$20-25$} \\
\hline & \multicolumn{4}{|c|}{64} & \multicolumn{3}{|c|}{135} \\
\hline $\begin{array}{r}\text { 2. The } \\
\text { preferable }\end{array}$ & Facebook & $\begin{array}{c}\text { Instagra } \\
\mathrm{m}\end{array}$ & $\begin{array}{c}\text { Skyp } \\
\text { e }\end{array}$ & $\begin{array}{c}\text { Google } \\
+\end{array}$ & $\begin{array}{c}\text { Linkedl } \\
n\end{array}$ & $\begin{array}{c}\text { Twitte } \\
r\end{array}$ & Other \\
\hline $\begin{array}{r}\text { social media for } \\
\text { communication } \\
\text { daily ( two } \\
\text { selected) }\end{array}$ & 149 & 115 & 29 & 14 & 9 & 41 & 37 \\
\hline $\begin{array}{l}\text { 3. Hours spent } \\
\text { for vesting } \\
\text { selected social }\end{array}$ & $\begin{array}{l}\text { Less than } \\
\text { one hour }\end{array}$ & $\begin{array}{c}1-2 \\
\text { hours }\end{array}$ & $\begin{array}{l}2-5 \\
\text { hours }\end{array}$ & \multicolumn{4}{|c|}{ More than 5 hours } \\
\hline $\begin{array}{r}\text { media sites } \\
\text { daily }\end{array}$ & 25 & 55 & 78 & \multicolumn{4}{|c|}{42} \\
\hline $\begin{array}{l}\text { 4. Preference for } \\
\text { building }\end{array}$ & \multicolumn{3}{|c|}{ Social media } & \multicolumn{4}{|c|}{ Face to face } \\
\hline $\begin{array}{r}\text { connection with } \\
\text { new friends }\end{array}$ & \multicolumn{3}{|c|}{94} & \multicolumn{4}{|c|}{106} \\
\hline
\end{tabular}




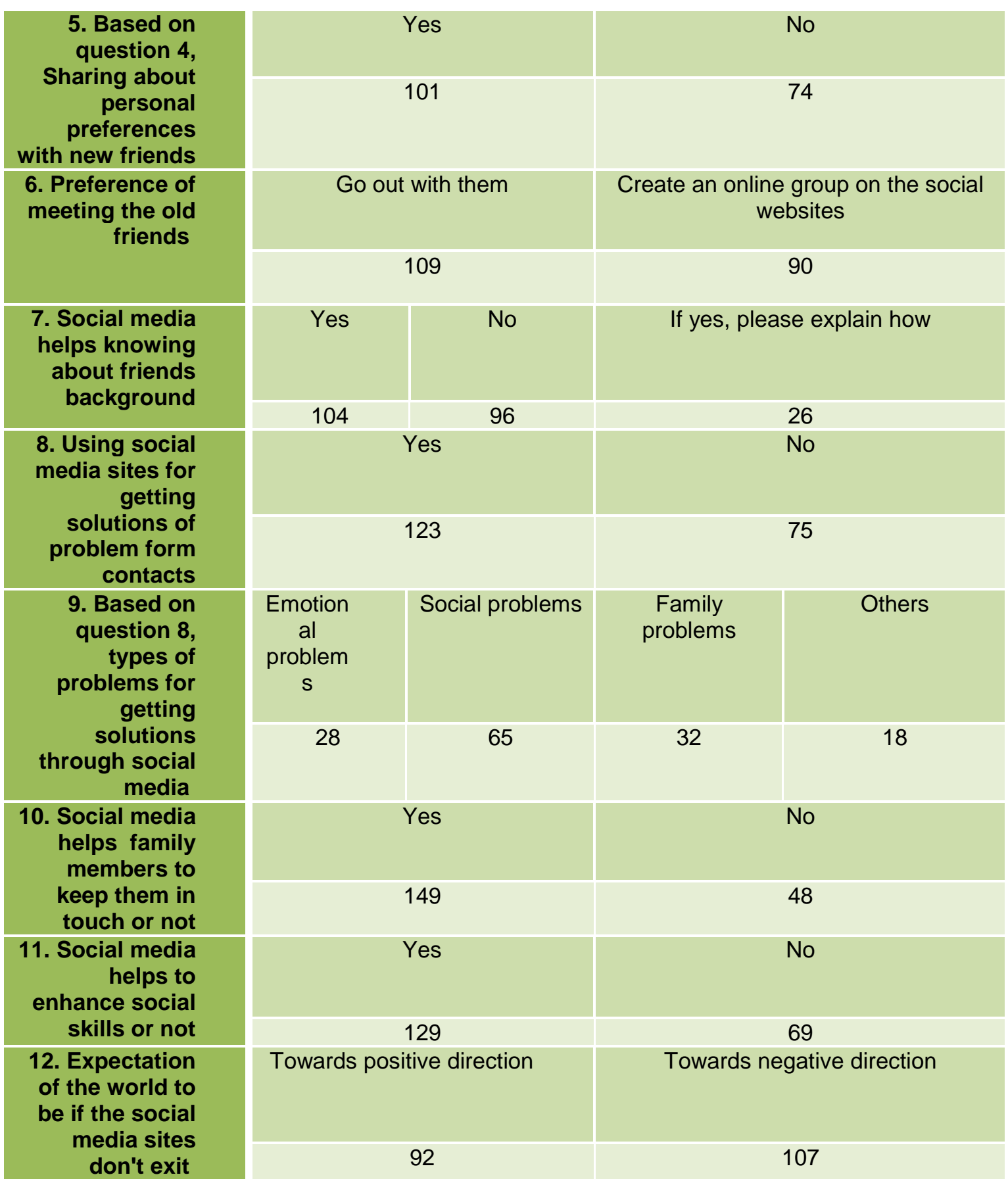

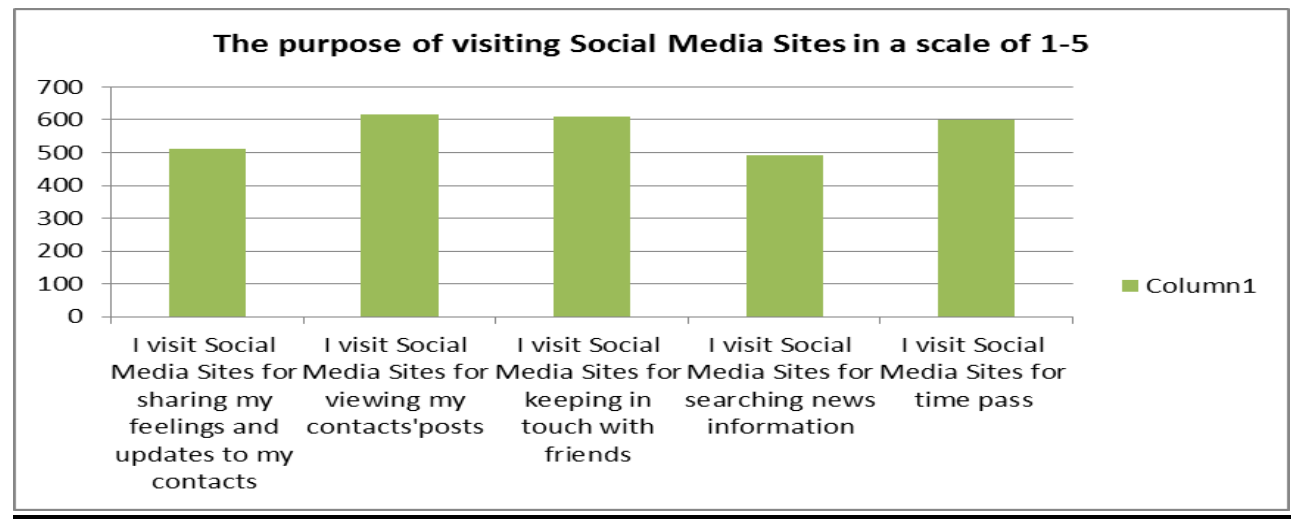

Fig. 1 
${ }^{*}$ These are the main reasons for browsing social media sites daily and our respondents have given their opinion on their main intention for browsing the sites in a 'scale' of 1 to 5 , where number 1 is strongly disagree, number 2 is disagree, number 3 is neutral, number 4 is agree and number 5 is strongly disagree.

\section{DISCUSSION}

The main target respondents of this survey are young adults from 15 to 25 years old. According to the survey results, $45.5 \%$ of the respondents are male and $54.5 \%$ of the respondents are female, while $31.2 \%$ of the respondents are between $15-20$ years old, and $67.8 \%$ of the respondents are between $20-25$ years old. The second question asked the young adults about their preference of the Social Media Sites they used daily to communicate with their contacts, and each respondent has selected the most two preferable sites. Facebook ranks at the top with $37.8 \%$, following Instagram as the second highest, with $29.2 \%$. Lastly, $9.4 \%$ the others such as WhatsApp, Snap Chat, KIK, BBM, Viber and Yahoo Messenger. These results prove that Facebook and Instagram are used mostly, because they have more entertainment facilities mainly uploading and commenting pictures. Moreover, through these sites people can create their own pages to share their skills worldwide.

In the third question of the survey we asked the young adults about the number of hours they spent in a day on their selected social media sites. 39\% of the respondents answered 2 to 5 hours daily while $12.5 \%$ of the respondents spent on their social media sites less than one hour. The reason why the majority spend many hours browsing the social media sites shows the fact that they are addicted on the facilities these sites provide and another reason is that is one of the ways they have to get rid of the monotony. In the table one, the young adults have given their opinion for the purpose of visiting social media sites in a scale of 1 to 5 . The highest purpose, $21 \%$, is for viewing their contacts post. One the other hand, the lowest percentages goes for searching news information, $17.4 \%$. The young adults have a natural tendency to check out the status of their friends every time they browse, so that they can comment and like them. However, they don't prefer reading news information because it is not within their interest compared to communication and entertainment.

The participants were asked in the fourth question about their preference to build connection with new friends. $53 \%$ of the respondents prefer to build connection with new friends face to face. In contrast, $47 \%$ of the respondents prefer to do so by using the social media. The majority prefers to build connecting with new friends face to face, because they are afraid of dealing with new people in a virtual world and they might not trust those people and their ideas at the beginning of relationship. There is still a big percentage $47 \%$ that shows how young adults prefer nowadays to build connection in the virtual world.

In the fifth question the participants were asked if they used the social media as their preferable tool to share information about themselves with new friends. The results was that the majority of $57.7 \%$ didn't mind discussing their personal matters because they get immediate responses from the other side and at the same time they don't feel shy to express what they have on their mind with the contacts as they don't have their facial expression. On the other hand, $42.3 \%$ of the respondent doesn't feel comfortable sharing their personal matter through social media because they don't trust everyone easily. In the question 6 , the participants were asked that if they would like to have fun with their old friends and would like to talk about different issues that they experience in life, how they would prefer to do so either by going out with them or by creating online group on Social Media Sites. $54.8 \%$ of respondents said that they would prefer to go out with old friends, and $45.2 \%$ respondents said that they would prefer to create an online group on Social Media Sites. The majority of the respondents prefers to meet old friends directly because they feel confident on discussing issues that require an agreement. In the question $7,57.5 \%$ of the respondents answered that Social Media does help them know about their friends' background better than face to face, and $42.5 \%$ of the respondents answered no it does not help. An additional question was asked to understand how it helped them know about their friends' background better if they answered yes. According to their point of view, many responded answered that their friends feel free to share whatever they have on their mind with others due to that the fact that they get more time for the discussion and they do not have to face the negative facial expressions of others. Furthermore, all the personal information are uploaded on every Social Media Site regarding who they are, so this is how young adults learn a lot about their friends' background and more easily than face to face. In the question $8,62.1 \%$ of the respondents answered yes for getting solutions of their problems from contacts, and $37.9 \%$ of the respondents answered no. Since there are many contacts added to their circles on Social Media, they can find the right person to discuss about their problems and get solutions efficiently. It is not always possible to find the right person who can fulfill the goals of others, so with the connection through Social Media, young adults can get whoever they want within a minute and get feedback quickly. In the question 9 , following up question 8 , the respondents were asked regarding the type of problem they would like to get solutions from their contacts. $45.5 \%$ of the respondents would like to get 
solutions for social problems, and $12.6 \%$ of the respondents answered for emotional or family related problems. According to the results, it is quite obvious that young adults step forward to get solutions of their social problems because they feel that their friends or contacts who they don't really know, can provide solutions the way they expect. When it comes to close friends or family members, their level of giving solutions to young adults will differ from others because they would not accept any unethical behavioral practices. Therefore, the youth share difficulties with virtual friends so they can get solutions according to their expectations. In the question $10,75.6 \%$ of the respondents answered yes, and $24.4 \%$ of the respondents answered no, if they thought that social media works as a helpful tool for the family members to keep in touch. In most instances, some family members are not always present, so it is convenient for them to interact with the youth through Social Media. In the question $11,65.2 \%$ of the respondents answered yes, and $34.8 \%$ of the respondents answered no, if they believed that Social Media helps to enhance their social skills or not. Social Media assists them to connect with different people from all over the world, so it helps them enhance their social skills. In the last question, the participants were asked if Social media sites didn't exist how the world would be and $53.8 \%$ of the respondents answered toward positive direction and $46.2 \%$ of the respondents answered towards negative direction. Those who believe towards negative direction, would like to spend more time visiting social media sites just for entertainment and for updating their status. However, those who believe towards positive direction are aware of the importance of the social media in their daily lives. So we found that social media affects the interpersonal communication negatively more than positively based on the previous statistics.

\section{CONCLUSION}

To conclude, it is true that social media serves as a helpful tool to connect with the people from across the world. According to the results of the survey, social media destructs the youth's interpersonal communication into a large degree. It is because the majority of young adults doesn't prefer to have any communication in a face to face setting in order to avoid any negative emotion, and they feel shy to open themselves up. Therefore, they feel comfortable to share their personal matter with those who are their virtual friends who they don't know well, because they get more time to discuss about a complex issue. So the provided recommendation is to guide the youth to be in the right track when using the social media for interpersonal communication.

\section{RECCOMENDATION}

Social media works as a helpful tool for the people especially the youth generation so they can contact their old friends and meet new ones. So if young adults exactly know how to use the social media effectively, they can benefit from the advantages and at the same time they can minimize the disadvantages. Firstly the young adults should know how to deal with their contacts on social media and chose whom to connect. Secondly, they should spend a balanced time to use the social media for any major purposes in order to avoid the negative consequences. Thirdly, they should not trust anyone immediately. Finally, they have to build strong ties with their families, close friends and other relatives, ecause they are the only ones they should trust.

\section{REFERENCE LIST}

Kaplan, M., Andreas, Haenlein Michael, (2010). Users of the world, unite! The challenges and opportunities of Social Media, Business Horizons Journal - ELSEVIER, pp. $59-68$.

Ghaffar, M. A., (2012). Social Media: Impacts on Arabian Gulf Youth and Governments, Bahrain Center For Strategic International and Energy Studies, p. 15.

Valley, S., (2015), Information Technology, The Levin Institute - The State University of New York , New York City.

Kemp, S., (2014), Social, Digital \& Mobile Worldwide in 2014,[Online]. Available: http://wearesocial.net/blog/2014/01/social-digital-mobile-worldwide-2014/.

Dainton, (2004), Explaining Theories of Interpersonal Communication,[Online]. Available: http://www.sagepub.com/upm-data/4984_Dainton_Chapter_3.pdf. [Accessed 35 2015].

"WHAT IS INTERPERSONAL COMMUNICATION?," [Online]. Available: http://www.crnb- 
rcnb.ca/en/files/what_is_interpersonal_communication_en.pdf. [Accessed 15 2015].

Staff, E., (2013), ICDL urges social media caution for GCC youth, [Online]. Available: http://www.emirates247.com/news/emirates/icdl-urges-social-media-caution-for-gcc-youth-2013-0527-1.508069. [Accessed 0305 2015].

Duggan, M., Nicole B., Ellison, Lampe, C., Lenhart, A., \& Madden, M., (2015), Social Media Update 2014, [Online].

Jain, D. R., (2010), 4 Ways Social Media Is Changing Your Relationships, [Online]. Available:

http://www.socialmediaexaminer.com/4-ways-social-media-is-changing-your-relationships/. [Accessed 35 2015].

"How to Enhance Interpersonal Communications Through Social Networks," [Online]. Available: http://www.wikihow.com/Enhance-Interpersonal-Communications-Through-Social-Networks. [Accessed 35 2015].

Al-Sayegh, F. H., (2013), The Impact of Social Media on UAE Society, The Emirates Center for Strategic Studies and Research, UAE.

Al-Sayegh, F. H., (2013), The Impact of Social Media on UAE Society,[Online]. Available: http://www.ecssr.ac.ae/ECSSR/print/ft.jsp?lang=en\&ftld=/FeatureTopic/FatmaAlSayegh/FeatureTopic_1698.xml. [Accessed 02 May 2015]. 